\title{
DIAMOND COATINGS THAT AFFECT DIAMOND RECOVERIES ON GREASE TABLES INVESTIGATED BY AN ELECTRON MICROPROBE
}

\author{
Steven A Cooper ${ }^{1}$, CM MacRae ${ }^{2}$, NC Wilson ${ }^{2}$, NVY Scarlett ${ }^{2}$ and WT Marx ${ }^{3}$ \\ ${ }^{1}$ Orogenic Exploration Pty Ltd, Australia; ${ }^{2}$ CSIRO Minerals, Australia $;{ }^{3}$ Tawana Resources NL, Australia.
}

Thin coatings have been observed on diamonds from two kimberlite pipes: Perdevlei K1 (PVM) and Kareevlei Wes (KVM), located $100 \mathrm{~km} \mathrm{NW}$ of Kimberly, in the Cape Province of South Africa (Figure 1). This thin layer of material, only visible with the use of a scanning electron microscope (SEM), enables the wetting of the diamonds thus preventing adhesion to the grease tables used in the separation of the diamonds from the kimberlite heavy mineral concentrate (Figure 2).

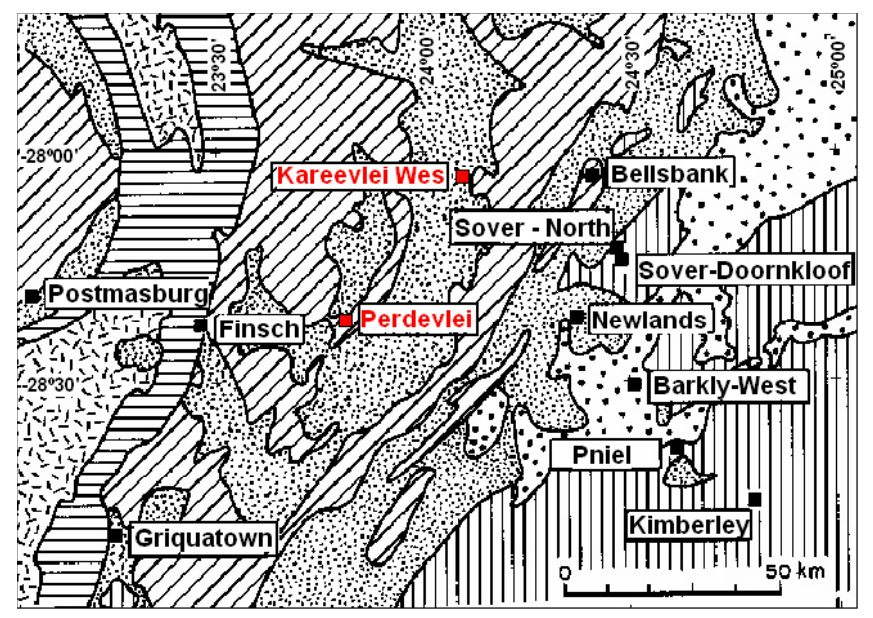

Figure 1: Kimberlite locations and geology of the Barkley West District, northwest of Kimberley. Based on figure in Mitchell (1995).

It is assumed that the mineralogy of the coating causes this unusual behaviour. To test this, six diamonds from the two pipes have been examined using a JEOL 8900R SuperProbe electron probe microanalyser (EPMA) equipped with wavelength dispersive X-ray spectrometers, an integrated cathodoluminescence (CL) spectrometer and electron detectors (MacRae et al., 2001). This EPMA offers a unique capability to collect $\mathrm{X}$-rays, electrons and the cathodoluminescence signal simultaneously in spatially resolved maps. The map data collected using this instrument has been analysed using in-house software (CHIMAGE, Harrowfield et al., 1993) that allows visualisation of the combined elemental and cathodoluminescence signals.

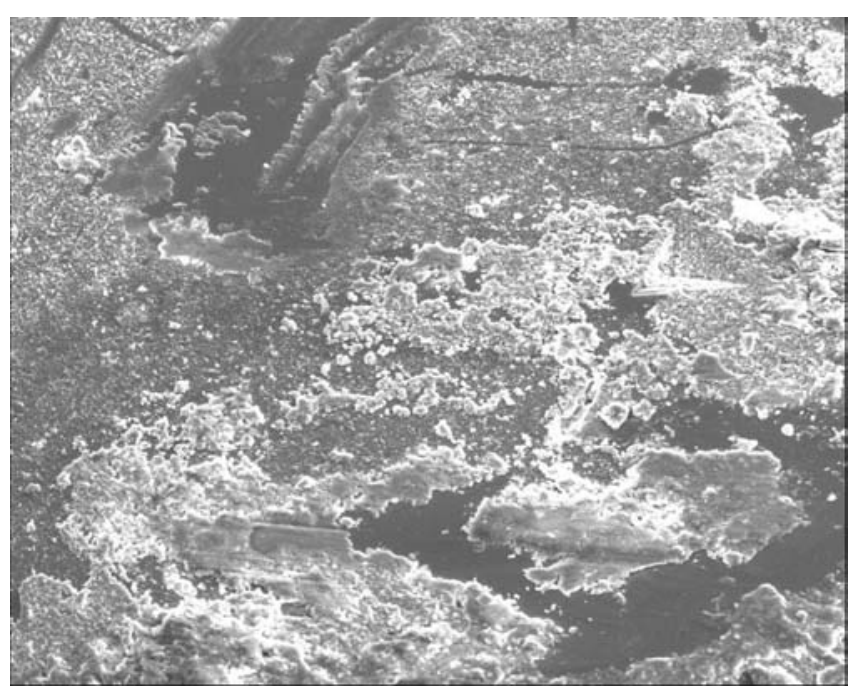

Figure 2: Secondary electron image of coating on diamond from PVM

\section{GEOLOGY}

The Perdevlei Kimberlite consists of a main diatreme (K1), which is an elongated dumbbell shaped pipe with a surface area of $1.7 \mathrm{Ha}$, and a small nearby satellite pipe (K2). It is covered by red soil and a calcrete cap varying in depth between 2 and 7 metres, and intrudes through the Palaeoproterozoic dolomites of the Campbell Group (Figure 3). All the diamonds studied from PVM are from this K1 pipe. Based on detailed petrology, the Perdevlei intrusion is an intensely carbonated, partly clay-degraded and oxidised (weathered), macrocrystal-bearing, partly autolithic and pelletal textured volcaniclastic diatreme facies orangeite (Group II Kimberlite). Some sections of the intrusion contain large fragments of rather massive, partly selectively altered, vesicular olivine dolerite which bestow on them a brown to black colour. In one sample late, possibly secondary blue amphibole (richterite?) was observed, suggesting an evolved primary composition (Mitchell. 1995).

The whole rock geochemistry for the two samples (collected at a depth of $31 \mathrm{~m}$ ) with the lowest Contamination Indices (CI; Clement, 1982) is provided in Tables 1 and 2. Both samples are contaminated and altered, but the $\mathrm{CI}$ is the best available. The range of 
the elements is similar to those reported for Orangeites by Mitchell (1995). In similar fashion to the Finsch Orangeite, both $\mathrm{Nb}$ and Ta appear to be depleted (Mitchell, 1995). The relatively high $\mathrm{Zr} / \mathrm{Nb}$ ratio supports an evolved Orangeite.

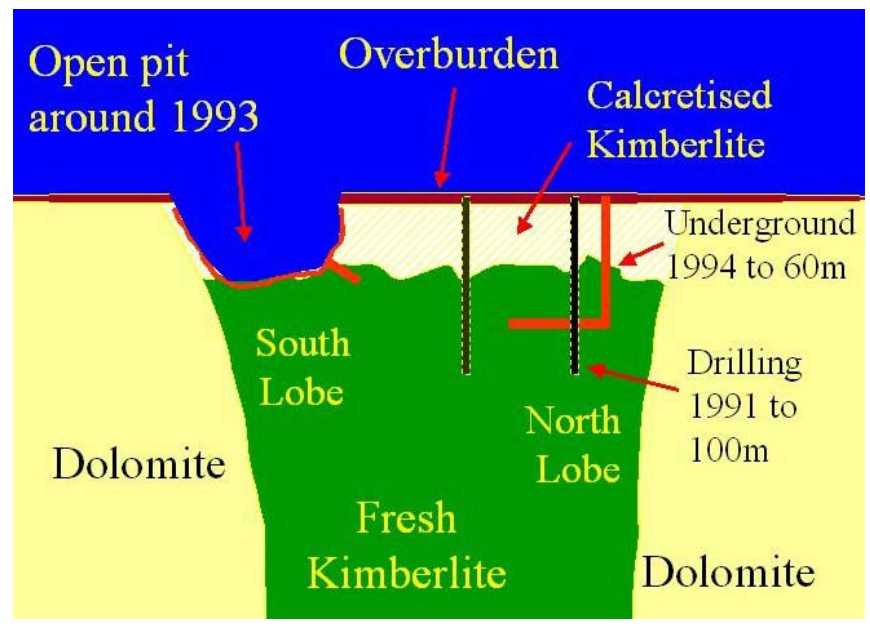

Figure 3. Cross section sketch of Perdevlei K1 looking west, showing activities completed prior to Tawana Resources NL.

\section{Table 1. Whole rock major oxide composition of two samples from PVM}

$\begin{array}{lrr}\text { Wt } \% & \text { PerdN } \mathbf{~} & \text { PerdN G } \\ \mathrm{SiO} 2 & 28.82 & 25.62 \\ \mathrm{Al} 2 \mathrm{O} 3 & 3.54 & 2.47 \\ \mathrm{Fe} 2 \mathrm{O} 3 & 6.59 & 5.75 \\ \mathrm{CaO} & 15.04 & 23.71 \\ \mathrm{MgO} & 18.89 & 13.71 \\ \mathrm{Na} 2 \mathrm{O} & 0.08 & 0.64 \\ \mathrm{~K} 2 \mathrm{O} & 1.01 & 0.76 \\ \mathrm{Cr} 2 \mathrm{O} 3 & 0.27 & 0.24 \\ \mathrm{TiO} 2 & 0.87 & 0.69 \\ \mathrm{MnO} & 0.17 & 0.11 \\ \mathrm{P} 2 \mathrm{O} 5 & 0.61 & 0.56 \\ \mathrm{SrO} & 0.06 & 0.06 \\ \mathrm{BaO} & 0.06 & 0.02 \\ \mathrm{LOI} & 23.99 & 25.64 \\ \text { Total } & 100 & 99.98\end{array}$

Little is known of the Kareevlei Wes intrusions, as there is no current outcrop and no available drill samples. There are six known separate pipes, the largest K3 is about 5.8 ha in area. Like Perdevlei they are covered by a calcrete cap with rare remnants of kimberlite texture visible (Figure 4.). Diamonds were reported in bulk sampling programs by previous explorers, but recovered diamond grades were lower than expected considering the favourable indicator mineral grain chemistry.

\section{Table 2. Whole rock trace element (ppm) composition of the same two PVM samples as Table 1.}

$\begin{array}{lrr} & \text { PerdN Y } & \text { Perd N G } \\ \mathrm{Ba} & 467 & 181 \\ \mathrm{Ce} & 86.1 & 103 \\ \mathrm{Co} & 49.8 & 51.7 \\ \mathrm{Cr} & 1200 & 1130 \\ \mathrm{Cs} & 1.5 & 0.3 \\ \mathrm{Cu} & 48 & 29 \\ \mathrm{Dy} & 2.1 & 2.2 \\ \mathrm{Er} & 0.9 & 1.1 \\ \mathrm{Eu} & 1.7 & 1.7 \\ \mathrm{Ga} & 7 & 6 \\ \mathrm{Gd} & 4.7 & 4.8 \\ \mathrm{Hf} & 5 & 5 \\ \mathrm{Ho} & 0.4 & 0.4 \\ \mathrm{La} & 44.7 & 53.1 \\ \mathrm{Lu} & 0.1 & 0.1 \\ \mathrm{Nb} & 40 & 40 \\ \mathrm{Nd} & 45.0 & 49.7 \\ \mathrm{Ni} & 627 & 632 \\ \mathrm{~Pb} & 12 & 11 \\ \mathrm{Pr} & 12.9 & 14.3 \\ \mathrm{Rb} & 39.2 & 16.1 \\ \mathrm{Sm} & 6.4 & 7.1 \\ \mathrm{Sr} & 526 & 529 \\ \mathrm{Ta} & 2.4 & 2.2 \\ \mathrm{~Tb} & 1 & 1 \\ \mathrm{Th} & 7 & 7 \\ \mathrm{U} & 0.9 & 1.1 \\ \mathrm{~V} & 68 & 71 \\ \mathrm{Y} & 8.6 & 9.6 \\ \mathrm{Yb} & 0.8 & 1.0 \\ \mathrm{Zn} & 55 & 40 \\ \mathrm{Zr} & 168 & 213 \\ \mathrm{Li} & 18.7 & 20.0 \\ \mathrm{Sc} & 13.4 & 12.4 \\ & & \\ \mathrm{Cr} & 5 & \end{array}$

The problem of diamond being wettable, and thus not sticking to grease has been reported in the Finsch Orangeite (Figure. 1), Mwadui (Williamson) Pipe, and the Tusilo plant in Angola (Bruton, 1978). To condition the concentrate a chemical reagent of Maize acid oil and caustic soda has been used in these 
operations. Similarly to both PVM and KVM, the Finsch Orangeite intrudes into dolomite.

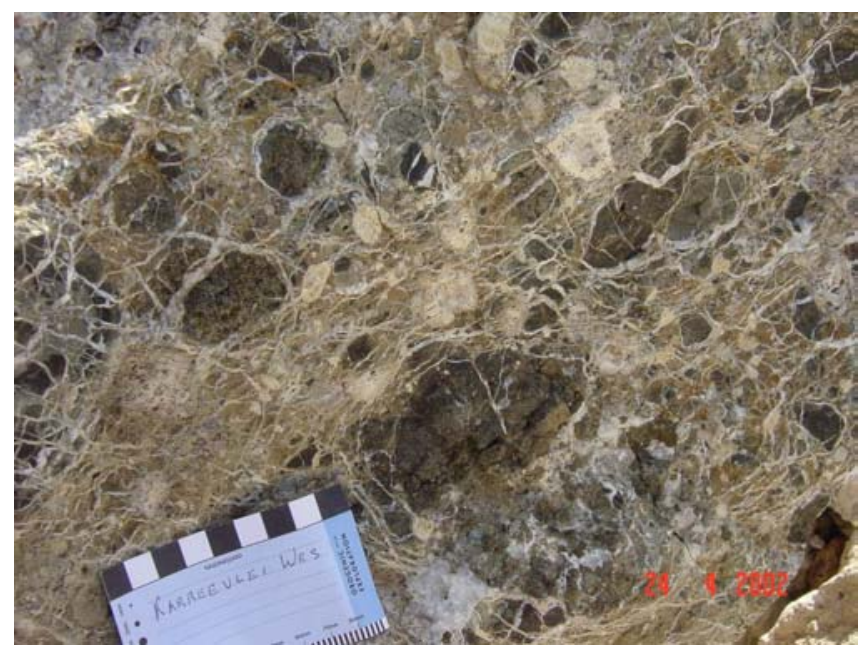

Figure 4: Photograph of rare boulder with relict kimberlite texture fragments within the calcrete overburden dump at Kareevelei West K2. Scale bar is in centimeters.

\section{EXAMINATION OF DIAMOND COATING}

A set of diamonds were mounted in epoxy and polished with progressively finer polish, the final polish being of $50 \mathrm{~nm}$ colloidal silica. This final polish was performed to minimise the amorphous layer on the diamond. If the amorphous layer is left intact it will filter the cathodoluminescence signal and obscure fine detail. Samples were coated with 20 nanometers of carbon prior to examination.

Coatings were observed under backscattered electron imaging and were found using energy dispersive X-ray spectrometery to contain a range of elements including $\mathrm{Fe}, \mathrm{Ca}, \mathrm{Al}, \mathrm{Si}, \mathrm{Ti}$ and $\mathrm{P}$. The thickness of the coatings ranged from 300 microns down to 50 microns and usually completely encapsulated the diamonds. Backscattered electron images reveal that the coatings are composed of particles ranging in size from 20 microns down to sub-micron (Figure $5 \mathrm{a}$ and $\mathrm{b}$ ). The coating is intimately bound to the diamond and has remained intact during the scrubbing process which has liberated the diamond from the ore. The particles are bound together with a compound that is yet to be identified. Calcium was observed in high concentrations and with little association to the other mapped elements suggesting, in this environment, the presence of calcium carbonate. Particles containing iron have also been observed as have separate silicon containing particles.
The simultaneous collection of CL with the usual X-ray and electron signals in spatial maps has significant advantages over traditional $\mathrm{CL}$ mapping in that it removes the need to have a priori knowledge about which frequencies will provide the solution to the problem. The CL signal is collected from a monocular eyepiece, which is integrated into the electron optics of the electron microprobe. The CL images reveal strong banding and crystalline forms within the diamonds (Panczer,et al., 2000) as seen in Figures 6 and 7. Diamonds from the KVM pipe show more complex crystalline banding than expected and this appears to be associated with inclusions that are present within these diamonds. The complex banding may suggest that these diamonds have been through a number of high pressure and temperature transitions during their formation. Diamonds from the PVM pipe show fine scale internal pores and voids indicating a different growth mechanism, compared to the KVM pipe.

\section{DISCUSSION}

Preliminary X-ray diffraction (XRD) investigations of the coatings have been carried out to try and ascertain their mineralogy. This has so far confirmed the presence of calcite, $\mathrm{CaCO} 3$ and rutile, $\mathrm{TiO} 2$ and suggested the possible presence of wustite, $\mathrm{FeO}$ and as yet, unidentified clay minerals (silicates). The mechanism of adhesion of these minerals to the diamond surface is not yet established.

If these coatings are common on diamonds within a kimberlite, then any diamond grade determinations based solely on the recoveries of grease tables would be seriously underestimated. The use of grease tables is common for bulk testing small kimberlites in southern Africa due to low capital costs involved. It may be that the assessment of many kimberlites to be barren or low grade for diamonds may simply be the consequence of using inappropriate diamond recovery techniques. Whether the coatings are dependent on the interaction of the country rock mineralogy, or the effects of the primary intrusive mineralogy is yet to be determined.

\section{ACKNOWLEDEMENT}

The authors wish to thank Tawana Resources NL for supplying the diamonds and permission to publish. Dr Jane Barron completed the petrological examinations. 


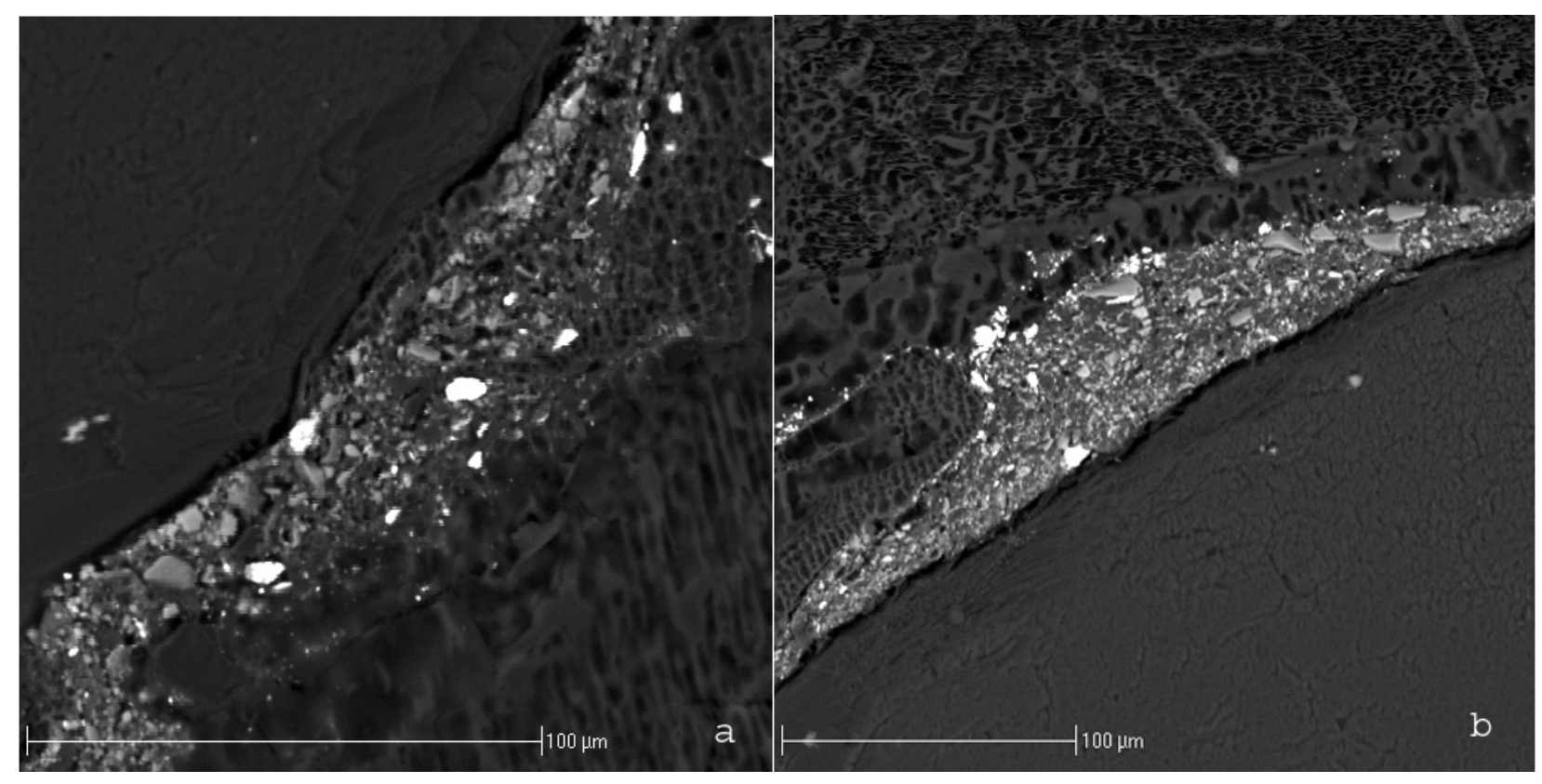

Figure 5. Backscattered electron images of coated diamond KVM-3 at $15 \mathrm{kV}$. The left top region in (a) is diamond, the lower right is epoxy, and the bright particles indicate a range of elemental compositions. Another view of this diamond is shown in (b).

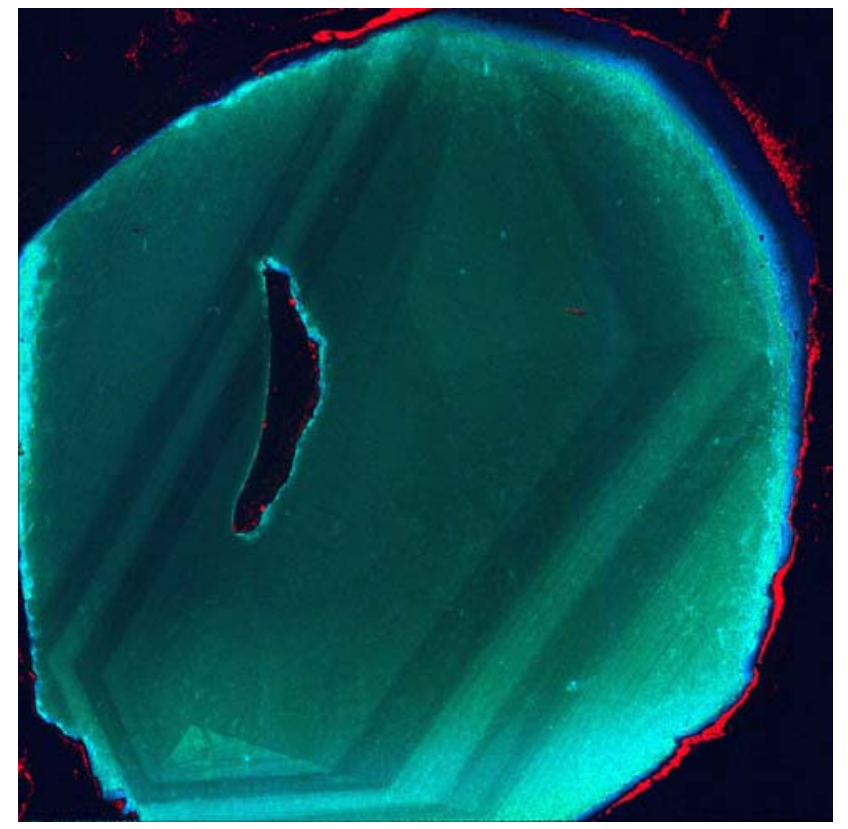

Figure 6. Combined cathodoluminescence (CL) and elemental X-ray map of KVM-3. CL frequency $400 \mathrm{~nm}$ is shown as blue, $\mathrm{CL}$ frequency $500 \mathrm{~nm}$ is green and $\mathrm{Ca}$ is red.

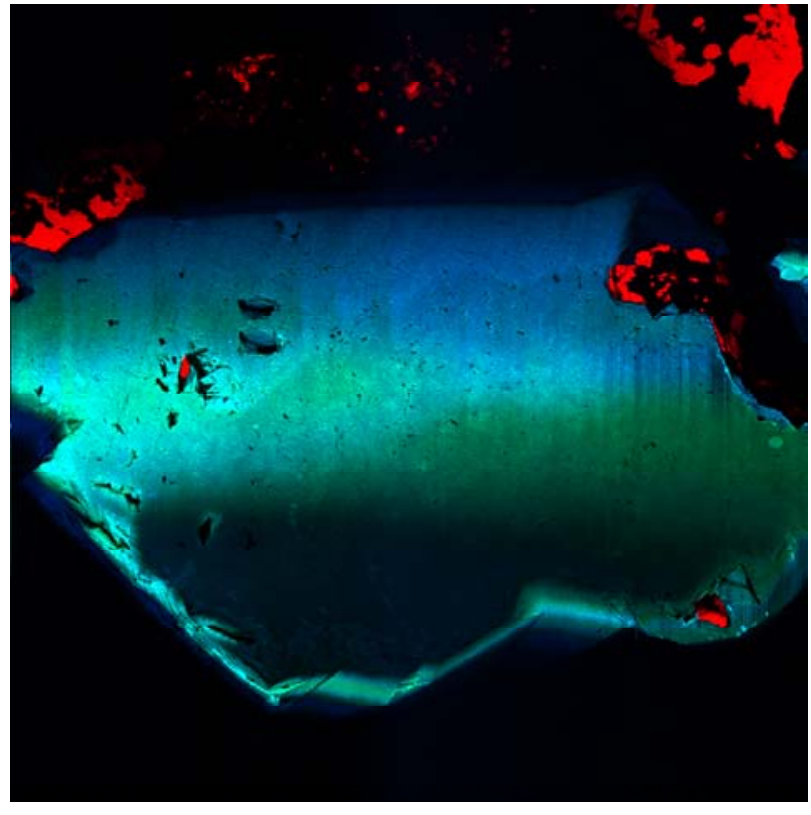

Figure 7. Combined cathodoluminescence (CL) and elemental X-ray map of PVM-2. CL frequency $400 \mathrm{~nm}$ is shown as blue, CL frequency $500 \mathrm{~nm}$ is green and $\mathrm{Ca}$ is red. Fig $2 \& 3$ indicate that calcium carbonate has precipitated around and within caverns into the diamond. 


\section{REFERENCES}

Bruton, E, 1978. Diamonds. Second Edition, Chilton Book Company, PA, USA.

Clement, C.R., 1982. A comparative geological study of some major kimberlite pipes in the Northern Cape and Orange Free State. Ph.D. thesis (2 vols), University of Cape Town, South Africa.

Davies, R.M., O'Reilly, S.Y., \& Griffin, W.L., 2002. Multiple Origins of Alluvial Diamonds from New South Wales, Australia. Economic Geology, 97, 109-123.

Hagni. R.D. 1987 (Ed.). Process Mineralogy Vol. VI: by. Proceedings of Metallurgical Society Annual Meeting. March 2-6 1986. Published.

Harrowfield I.R., MacRae C., \& Wilson N.C., 1993. Chemical imaging in the electron microprobe. Pp. 547-548. Proceedings of the $27^{\text {th }}$ Annual
MAS meeting. (Australian Microbeam Analysis Society) 1993

MacRae, C.M., Wilson, N.C., \& Otsuki, M., 2001. Holistic mapping in an Electron Microprobe. In Proceedings of the $27^{\text {th }}$ Annual MAS meeting. (Microbeam Analysis Society) 2001, 146-147.

Mitchell, R.H., 1995. Kimberlites, Orangeites, and Related Rocks. Plenum Press.

Pancer, G., Gaft, M., \& Marfunnin, A.S., 2000. Systems of Interacting Luminescence Centres in Natural Diamonds: Laser-Induced Time-Resolved and Cathodoluminescence Spectroscopy. In Pagel, M., Barbin, V., Blanc., P., \& Ohnenstetter, D., (Eds.) Cathodoluminescence in Geosciences. Springer Verlag.

Contact: Steven Cooper, 5 Glengarry Ave, Burwood, Vic, Australia, 3125, E-mail: StevenACooper@compuserve.com 